Article

\title{
Optimization of Thermal Parameters of the Coke Oven Battery by Modified Methodology of Temperature Measurement in Heating Flues as the Management Tool in the Cokemaking Industry
}

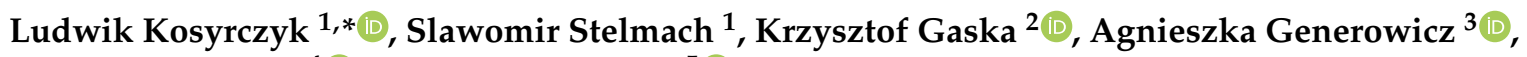 \\ Natalia Iwaszczuk ${ }^{4}$ (D) and Dariusz Kardaś ${ }^{\text {(iD) }}$
}

Citation: Kosyrczyk, L.; Stelmach, S.; Gaska, K.; Generowicz, A.; Iwaszczuk, N.; Kardaś, D. Optimization of Thermal Parameters of the Coke Oven Battery by Modified Methodology of Temperature Measurement in Heating Flues as the Management Tool in the Cokemaking Industry. Energies 2021, 14, 904. https:// doi.org/10.3390/en14040904

Academic Editor:

Dimitrios Katsaprakakis

Received: 19 December 2020

Accepted: 2 February 2021

Published: 9 February 2021

Publisher's Note: MDPI stays neutral with regard to jurisdictional claims in published maps and institutional affiliations.

Copyright: (c) 2021 by the authors. Licensee MDPI, Basel, Switzerland. This article is an open access article distributed under the terms and conditions of the Creative Commons Attribution (CC BY) license (https:// creativecommons.org/licenses/by/ $4.0 /)$.
1 Institute for Chemical Processing of Coal, Zamkowa 1 St, 41-803 Zabrze, Poland; sstelmach@ichpw.pl

2 Department of Water and Wastewater Engineering, Silesian University of Technology, Konarskiego 18 St, 44-100 Gliwice, Poland; krzysztof.gaska@polsl.pl

3 Department of Environmental Technologies, Cracow University of Technology, Warszawska 24 St, 31-155 Cracow, Poland; agenerowicz@pk.edu.pl

4 Faculty of Management, AGH University of Science and Technology, Gramatyka 10 St, 30-076 Cracow, Poland; niwaszcz@zarz.agh.edu.pl

5 The Szewalski Institute of Fluid-Flow Machinery, Polish Academy of Science, Fiszera 14 St, 80-231 Gdańsk, Poland; dk@imp.gda.pl

* Correspondence: lkosyrczyk@ichpw.pl

\begin{abstract}
Coke production is still of great economic importance due to its crucial role in the steel production process. The reliability of the operation of coke oven batteries depends on the maintenance of good technical condition of their ceramic massif, which in turn requires ensuring proper operation of the heating system and maintaining temperature stability in the heating flues. Regularly performed temperature measurements in heating flues due to the size of the battery and the dynamics of accompanying processes do not reflect the actual thermal state of the object at a given time. Corrections commonly introduced to the results of temperature measurements in heating flues, taking into account so-called reversion, significantly improve the accuracy of the obtained measurement results. However, still the interpretation of the results of temperature measurements in the coke oven battery heating flues does not take into account its changes during the coking cycle, even though they reach up to $60 \mathrm{~K}$. The article discusses the usability of the introduction of a new, additional correction to the temperature measured in the heating flues enabling a more precise assessment of the current thermal state of the coke oven battery. The use of the method will allow for reduction of the fuel gas consumption and limitation of emissions resulting from its combustion and can be used as an effective tool for decision making.
\end{abstract}

Keywords: coke oven battery; heating flues; temperature measurement; temperature adjustment

\section{Introduction}

The European Commission has maintained coking coal's status as a Critical Raw Material in 2020 treated it as the raw materials with a high supply-risk and a high economic importance for European industry and value chains. Poland (Jastrzębska Spółka Weglowa) is the largest producer satisfying nearly $20 \%$ of the annual demand of the European steel industry. Increasing the efficiency of the coke production process by optimizing the thermal parameters can have positive impact both on economic and environmental performance as the coking process is one of the most important thermochemical coal processing technology. In general, the fundamentals of the process have not changed over a hundred years. It involves the diaphragm heating of coking coal in rectangular, ceramic chambers (furnaces) at a temperature of $\sim 1173-1273 \mathrm{~K}$ (in the center of coal charge) and in anaerobic conditions. 
The heating of the chambers is obtained from the exhaust gases generated in the combustion of coke oven gas formed during the devolatilization of the processed coal. In simplified terms, it can be said that a coke oven battery comprises of ceramic chambers arranged in series and separated by vertical heating flues. A general diagram of the cross-section of the coke oven battery is presented in Figure 1.

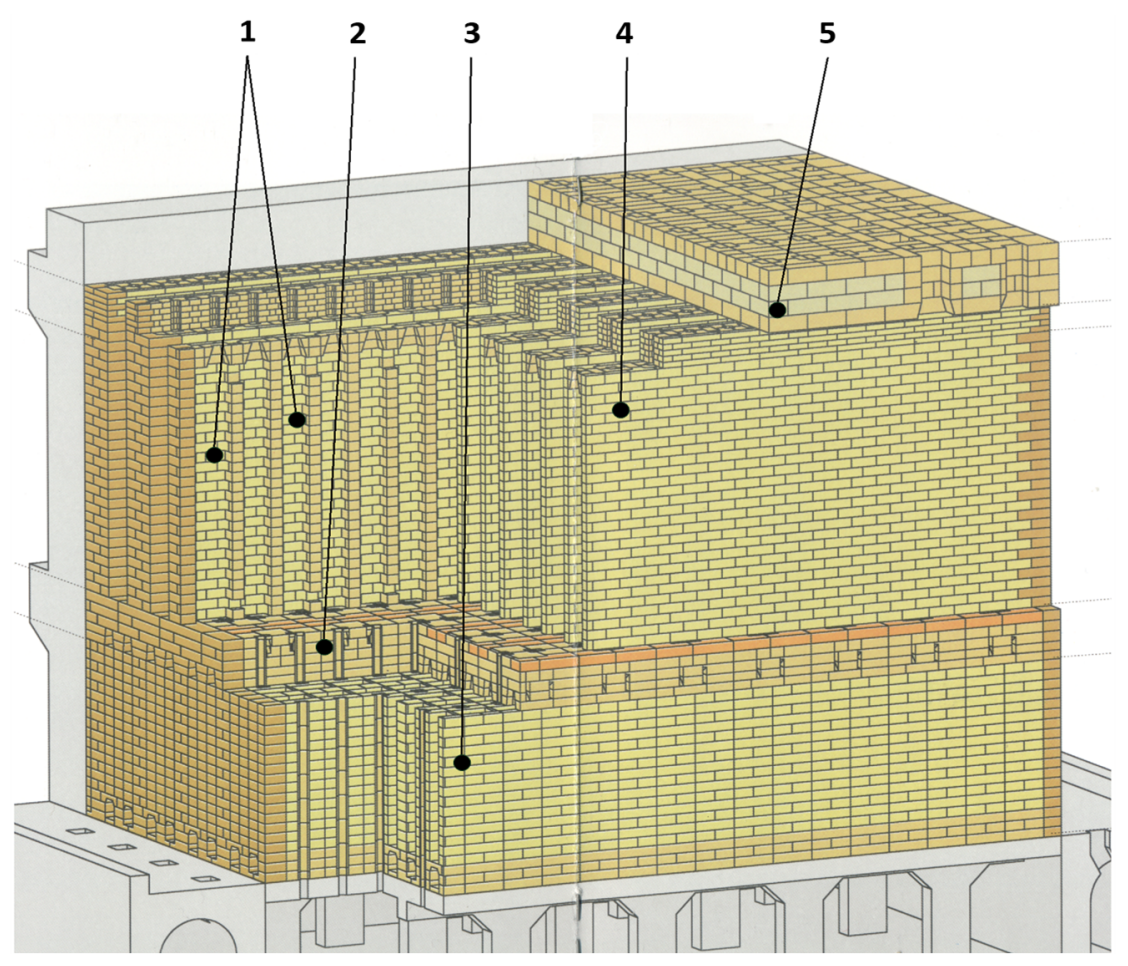

Figure 1. Cross-section of the coke oven battery (1-heating flues, 2-coking chamber shaft and floor, 3-regenerators, 4-brickwork of coking chambers and heating walls, 5-vault and roof).

Great developments in recent years have been done particularly aimed at minimising emissions from the cokemaking processes and at improving working conditions for coke oven batteries operators. But still the operation of heating/firing of the coke oven battery dominate the emissions from a coking plant. The smooth and undisturbed operation of the coke oven batteries is one of the most important process-integrated measures for emissions control and minimization. Automation of the coke production enables a coking plant to be operated at optimum efficiency. According to R. Remus et al. [1], one of the control option of thermal state of coke oven battery is manual measurements of the temperature at the heating flues using an infrared pyrometer with an integral data memory. In all Polish coking plants, temperature measurements in the heating flues of coke oven batteries are performed in this way. It is a well-proven technical management tool for control of the thermal condition of a coke oven batteries in Poland and abroad.

The operation of the coke oven battery requires constant monitoring of many operational parameters and appropriate response to occurring disruptions. One of the most important operating parameters of a coke oven battery is the temperature maintained in heating flues. Despite the search for various precise and continuous methods for controlling the coking process, its monitoring is based on the establishment of the thermal parameters selected individually for given coke oven furnaces [2]. Proper selection of the temperature of individual coke oven battery heating flues is crucial for the correct course of the pyrolysis process of the coal blend (with or without other additives, e.g., biomass, plastics, etc. [3]) used to produce coke, as well as the durability of its ceramic massif and the energy consumption of the production process. Preventing damages of the ceramic massif by maintaining the stable temperature allows for long-term, uninterrupted 
operation of the coke oven battery and ensures its reliable operation. Due to these facts, the operators of each coke oven battery perform mandatory, periodic temperature measurements in selected heating flues of each of its heating walls. For the PWR-63 coking battery (designed by Koksoprojekt, Zabrze, Poland), typically used in Polish coke oven plants, which consists of 78 heating walls and 30 heating flues on each of them, these measurements cover the monitoring of 156 heating flues for a single campaign (two heating flues on each wall). Based on the results, the amount of fuel gas supplied to the entire battery and its individual heating walls is adjusted. Temperature measurements at the bottom of the heating flues are performed using a digital pyrometer with internal memory. The results are transferred from the internal memory to the computer control system of the coke oven battery. Reliable interpretation of the results of temperature measurements, however, create major difficulties for battery operators, mainly due to the fact that the battery is a dynamic object, characterized by high variability of local temperatures over time. Numerous measurements of the temperature in the heating flues have confirmed that regardless of the correct selection and maintenance of stable parameters of coke oven gas combustion (coke oven gas and air stream supply and the temperature of the flue gas) in all industrially operated coke oven batteries (regardless of the design), there is always a certain temperature variation, along with the height of the heating flue and in time [4]. First of all, this is due to the dynamics of flame spread and the heat transfer characteristics in the specific heating flue design. The intensity of diffusive gas combustion (which is the only one taking place in coke oven battery heating flues) depends mainly on the concentration of combustible components of fuel gas (coke oven gas) and oxygen at a specific point of the heating flue [5-7]. This, despite many upgrades in the design of heating flues, significantly improving its alignment along their height (changes in the spacing of air and gas inlets, different height of burners, use of recirculation, gradual air supply at different heights, etc.), is still different at each point. Computer simulations using computational fluid dynamics (CFD) of the gas combustion process inside the PWR-63 battery heating flue (with internal exhaust gas recirculation) have shown that difference of exhaust gas temperature along its height (even with uniformly distributed, unrealistic heat reception) can reach several dozen degrees, regardless of the adopted conditions for heating media supply (with the exception of the excess air coefficient, which slightly influences on this distribution) [8]. In addition, as noted by Huhn [9], due to the diversified density and humidity distribution of the coal blend in the chamber, the heat receiving conditions in different zones of the chamber (along the length and height of the coal charge) are different. These factors, even with mutual compensation and the significant impact of the accumulation of ceramic massif, cause a variation in temperature not only on the surface of the coking chamber, but also on the walls of heating flues. The measurements of the brickwork temperature in selected PWR-63 battery heating flues at several heights showed, in line with the expectations arising from the discussed facts, variation in temperatures reaching up to $100 \mathrm{~K}$, both in the gas combustion phase and in the combustion cut-off phase (Figure 2). Each of these phases typically takes $20 \mathrm{~min}$. The brickwork of the coking chambers is made of silica with a thermal conductivity at its operating temperature (about $1373 \mathrm{~K}$ ) of $1.8 \mathrm{~W} /(\mathrm{mK})$.

The correct temperature measurement in coke oven battery heating flues and the appropriate interpretation of the obtained results require an unambiguous reference location where these measurements should be made. At domestic coking plants, this rule does not arise any controversy, and the place of measuring temperatures in heating flues is for all batteries either on the surface of the burner or on the surface of the brick separating the oblique channels (air inlet). It has to be pointed out, however, that the selected place of measurement of the temperature of the heating flue wall does not represent either the highest temperature or the average value of the entire flue. 


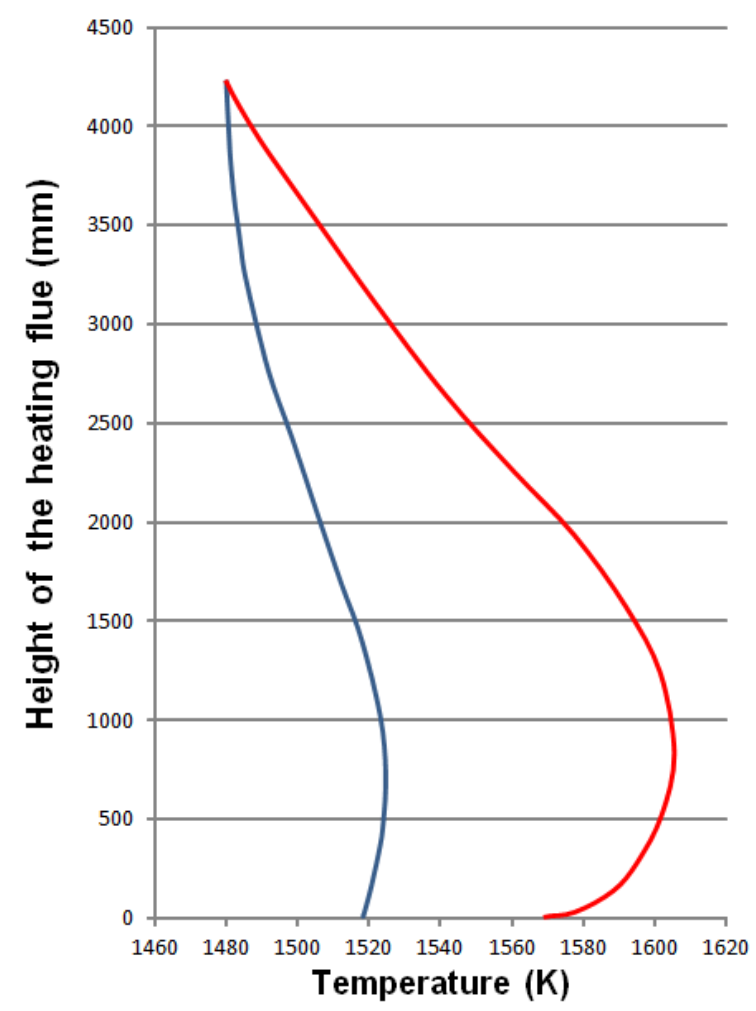

Figure 2. The diagram of an exemplary temperature distribution along the height of the PWR-63 battery heating flues. The red line shows the 15th min of the combustion phase. The blue line shows the 17 th $\min$ of the combustion cut-off phase.

There is also no controversy when interpreting the results of temperature measurements in heating flues, taking into account the correction for its periodic decrease between reversions (switching the direction of exhaust gas flow). As shown by tests carried out on the batteries of China Steel Corporation [4], during the combustion cut-off in a given heating flue, at each of its points there is almost an exponential decrease in temperature over time (Figure 3). This decrease for each battery and specific measurement location is easily determined by measuring the temperature in several selected heating flues of a given battery at one-minute intervals and averaging the obtained results.

Since the temperature measurements in the heating flues are made over the length of the battery at different time from the moment the gas combustion is turned off, in order to assess the actual temperature in a given time, all results are reduced to the moment of the burners turn off, applying the suitable corrections discussed in previous paragraph.

The current interpretation of the results of temperature measurements in the heating flues does not take into account its changes, which occur during the coking cycle, although (as research has proved [2,4,9]) these changes reach up to $60 \mathrm{~K}$ (Figure 4).

The nature and magnitude of these temperature changes are mainly due to the fact that the heat is consumed unevenly by the coal charge, while the supply of the heat by the heating flues is relatively constant. Because each of the coking chambers during the measurement of temperatures in the heating flues of the heating walls is at a different stage of the process, a natural variation of the results of temperature measurements in the heating flues is noted, regardless of other factors such as temperature drop between reversions, incorrectly selected gas and air dosages, damages in ceramic massif, or incorrect loading of the chamber. In addition, each alternating sequence of temperature measurements in the heating flues is carried out at a different moment of the coking cycle occurring in each chamber. Thus, the observed difference from the previous measurement does not coincide with the difference from the next measurement. Hence, in order to assure a reliable assessment of the real temperature in individual heating flue, an unambiguous 
way of assessing their variability during the entire coking process needed to be urgently developed, and it was done by actions discussed in this article.

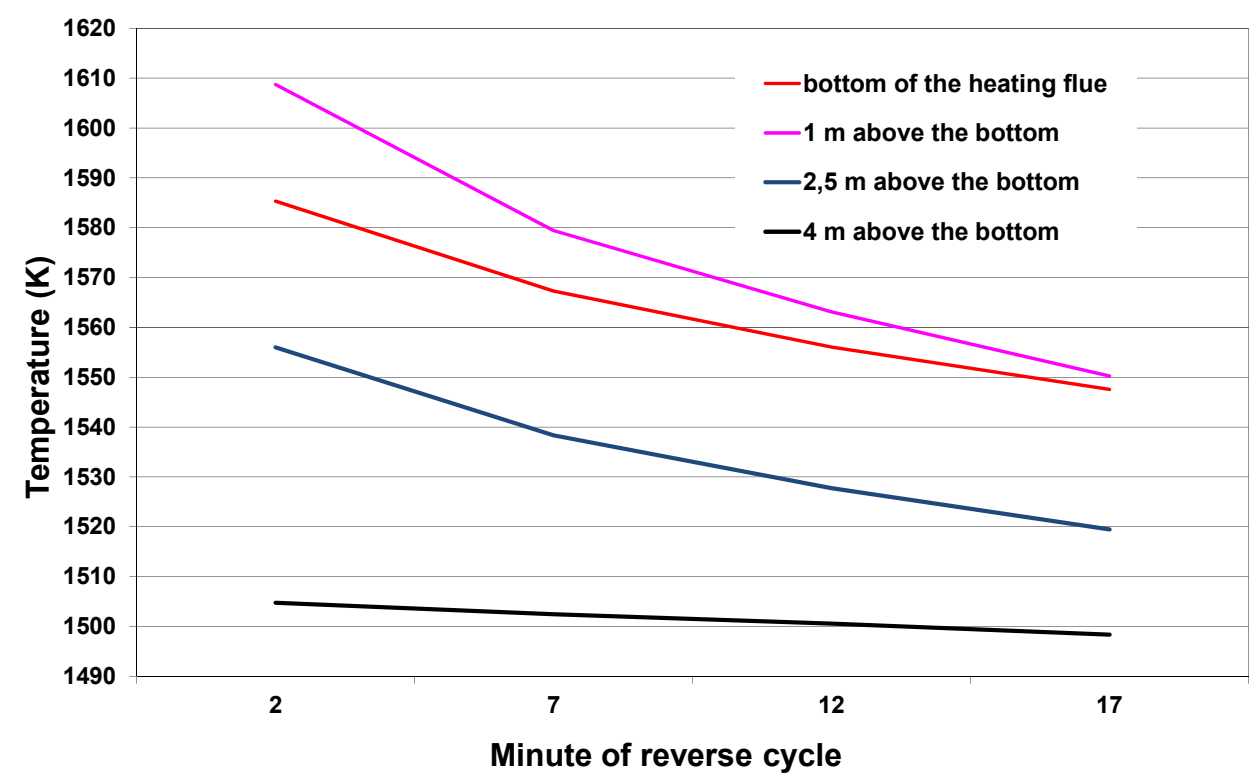

Figure 3. The exemplary temperature changes in the heating flues during the reverse cycle observed for PWR-63 battery.

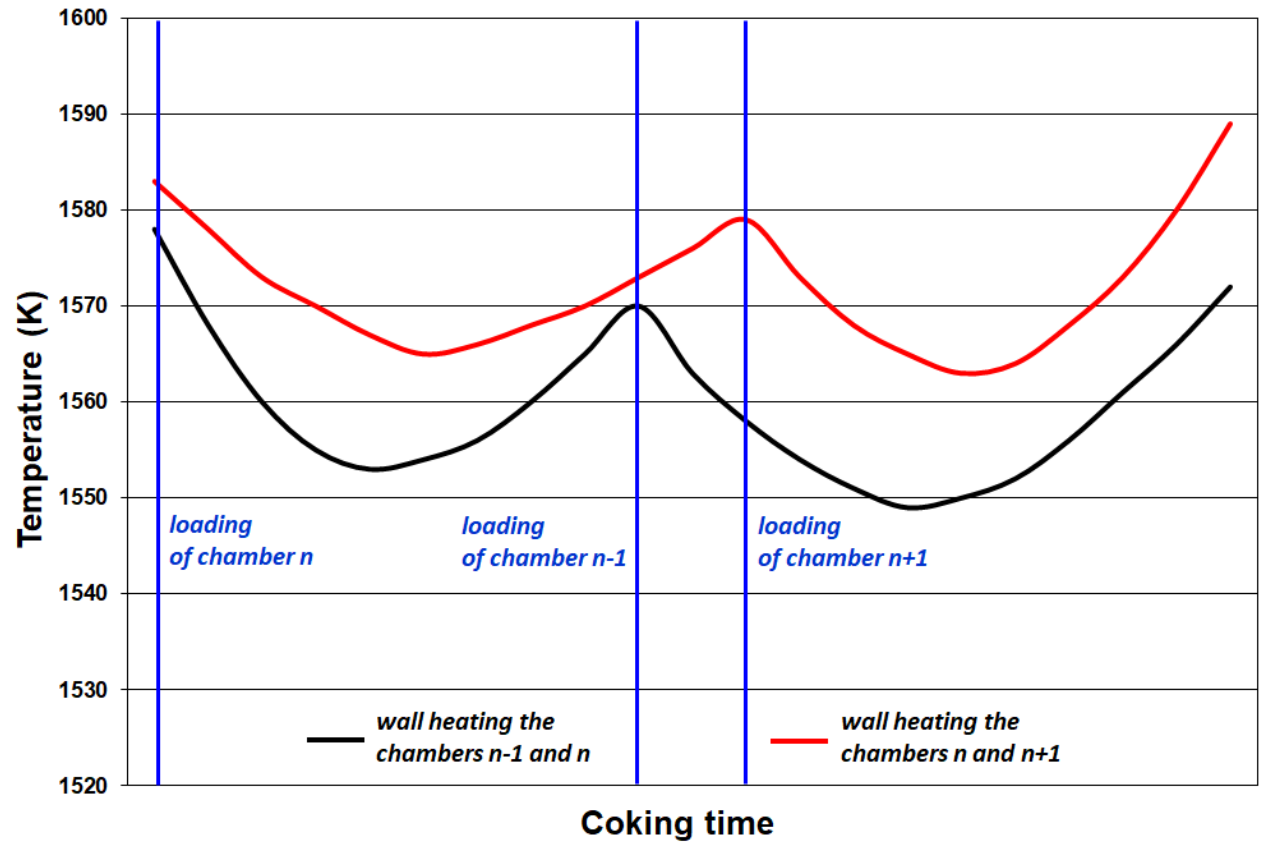

Figure 4. Temperature changes during the coking process on the bottom of the heating flues for two adjacent heating walls measured at one of the Polish coke oven battery [2].

\section{The Concept of a New Method for Assessing Temperature in Heating Flues}

The conventional coking process involves the heat transfer of the required level through ceramic of each of the coke oven battery heating flues to a coal charge loaded in the chamber at a given time. The pyrolysis process, which occurs as a result of the coal charge temperature increase, leads to the production both hot coke and volatiles-raw gas, tar and benzol (and sometimes even soot when the coking process is not conducted properly [10]). Since the heat demand for the pyrolysis process in the subsequent intervals of the coking 
cycle is diversified, considering its constant supply during stable battery operation, there are consequently observed temperature changes in the heating flues.

Due to this fact, an attempt was made to develop a clear interpretation of temperature measurement results in heating flues by introducing an additional new correction for its variability during the entire coking process. It was assumed that if there was a correction for temperature drop between reversions, a similar correction could be developed for the progress of the pyrolysis process.

In order to match the result of each measurement on a given wall to the same process advancement in the adjacent chamber, it was assumed that the temperature changes in the brickwork of heating flues adjacent to it could be presented for practical considerations as shown in Figure 5:

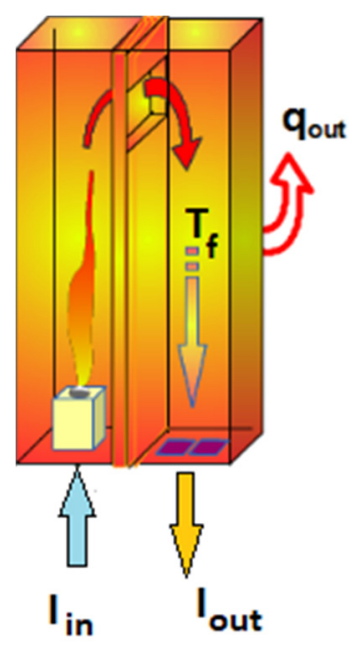

Figure 5. The scheme of heat flow in the heating flues of a coke oven battery.

The energy balance of heating flues of a coke oven battery shown in Figure 5 was next described as shown in Equation (1):

$$
\frac{d \rho_{f} V_{c h} c_{p f} T_{f}}{d \tau}=i_{\text {in }} \frac{d m_{\text {in }}}{d \tau}-\frac{d m_{\text {out }} i_{\text {out }}}{d \tau}+\frac{d I_{c}}{d \tau}-\frac{d Q_{\text {out }}}{d \tau}
$$

where:

- $\quad \varrho_{f}(\tau)$ : flue gas density $\left(\mathrm{kg} / \mathrm{m}^{3}\right)$

- $V_{c h}$ : volume of heating flue $\left(\mathrm{m}^{3}\right)$

- $\quad c_{p f}$ : average flue gas heat capacity $(\mathrm{J} /(\mathrm{kg} \mathrm{K}))$

- $T_{f}(\tau)$ : flue gas temperature in the heating flue in time $\tau(\mathrm{K})$

- $\quad i_{\text {in }}(\tau)$ : specific inlet enthalpy $(\mathrm{J} / \mathrm{kg})$

- $\quad m_{\text {in }}(\tau)$ : inlet mass $(\mathrm{kg})$

- $i_{\text {out }}(\tau)$ : specific outlet enthalpy $(\mathrm{J} / \mathrm{kg})$

- $m_{\text {out }}(\tau)$ : outlet mass $(\mathrm{kg})$

- $I_{c}(\tau)$ : combustion enthalpy $(\mathrm{J})$

- $Q_{o u t}(\tau)$ : heat flux discharged from a given heating flue in time $(\mathrm{J})$

The inlet mass flow $m_{\text {in }}$ does not change with time. The enthalpy of combustion $I_{c}$ is also constant over time. Hence, the first and third terms on the right side of Equation (1) are zero and this equation takes the form:

$$
\frac{d \rho_{f} V_{c h} c_{p f} T_{f}}{d t}+m_{\text {out }} \frac{d c_{p f} T_{f}}{d t}=-\frac{d Q_{o u t}}{d t}
$$


Assuming that the functions of density and specific heat do not depend on time and using formula on the heat flux $Q_{o u t}=A q_{\text {out }}$, it can be written in the form of the following differential equation:

$$
\left(\rho_{f} V_{\text {ch }}+m_{\text {out }}\right) c_{p f} \frac{d T_{f}}{d t}=-A \frac{d q_{\text {out }}}{d t}
$$

where $A$ is heat transfer area, $q_{\text {out }}$ means density of heat $\left(\mathrm{J} / \mathrm{m}^{2}\right)$.

It follows from the above that the change in gas temperature is proportional to the heat given off to the outside:

$$
\Delta T_{f}(\tau)=-\frac{A}{\left(\rho_{f} V_{\text {ch }}+m_{\text {out }}\right) c_{p f}} \Delta q_{\text {out }}(\tau)
$$

It can be stated that the problem of temperature changes covering each heating flue during the coking cycle lays in determination of the changes in the heat flux $\left(\Delta q_{\text {out }}(\tau)\right)$, which is proportional to a certain value (C) (Equation (5)):

$$
\Delta T_{f}(\tau)=C \cdot \Delta q_{\text {out }}(\tau)
$$

Heat transfer in the area of the heating wall (diaphragm) and coking coal charge with unidirectional flow can be described by the following relationships (Equations (6)-(8)):

- heat flux transmitted to the wall:

$$
-\left.\lambda \cdot \frac{\partial T_{w}(x, \tau)}{\partial x}\right|_{x=0}=\alpha \cdot\left(T_{f l}(\tau)-T_{w}(0 . \tau)\right)
$$

where:

$\lambda$ heat transfer coefficient of the wall material $(\mathrm{W} /(\mathrm{m} \times \mathrm{K}))$,

$x$ linear dimension $(\mathrm{m})$,

$\tau$ time (s),

$\alpha$ heat transfer coefficient from the heating flue to the wall $\left(\mathrm{W} /\left(\mathrm{m}^{2} \mathrm{~K}\right)\right)$,

$T_{f l}$ flame temperature $(\mathrm{K})$,

$T_{w}$ wall temperature $(\mathrm{K})$,

- heat conduction in the wall [11]:

$$
\frac{\partial\left(\rho \cdot c_{p} \cdot T_{w}\right)}{\partial \tau}=\frac{\partial}{\partial x_{i}}\left(\lambda \cdot \frac{\partial T_{w}}{\partial x_{i}}\right)
$$

where:

$\rho$ wall material density $\left(\mathrm{g} / \mathrm{m}^{3}\right)$,

$c_{p}$ specific heat of the wall material $(\mathrm{J} /(\mathrm{g} \cdot \mathrm{K}))$,

- heat conduction in the coal charge [11]:

$$
\frac{\partial\left(\rho_{c} \cdot c_{p c} \cdot T_{c}\right)}{\partial \tau}=\frac{\partial}{\partial x_{i}}\left(\lambda_{c} \cdot \frac{\partial T_{c}}{\partial x_{i}}\right)+\frac{Q_{p}}{T_{2}-T_{1}}\left(\frac{\partial T_{c}}{\partial \tau}\right)
$$

where:

$\rho_{c}$ density of coal charge $\left(\mathrm{g} / \mathrm{m}^{3}\right)$,

$c_{p c}$ specific heat of coal charge $(\mathrm{J} /(\mathrm{g} \times \mathrm{K}))$,

$T_{c}$ coal charge temperature $(\mathrm{K})$,

$\lambda_{c}$ coal charge thermal conductivity $(\mathrm{W} /(\mathrm{m} \times \mathrm{K}))$,

$Q_{p}$ thermal effect of the pyrolysis process $\left(\mathrm{J} / \mathrm{m}^{3}\right)$,

$T_{1}, T_{2}$ temperature range in which the coking process takes place $(\mathrm{K})$

The solutions of the above equations allow to calculate temperature distributions at individual points of the coal charge and the heating wall, as well as changes in the analyzed 
heat fluxes during the entire coking process. Moreover, some of the results of calculations for exemplary pyrolysis conditions have already been presented by M. Sciazko et al. [12]. Average heat effect of the pyrolytic reaction for the overall coking period is exothermic and, in dependence of the coal type, ranges from -5 to $-50 \mathrm{~kJ} / \mathrm{kg}$. Thus, the proposed model can be used to analyze many other pyrolytic processes because it also takes into account the heating rate [13]. Interesting for determining the temperature changes of heating flues during the entire coking process is the characteristics of changes in heat flux transmitted to the wall. Analyzing the average theoretical characteristics of these changes (Figure 6), it can be stated that in the initial phase of the coking process the heat consumption gradually increases, next it starts to slowly decrease and in the last phase it quickly decreases. Coking phases are presented in the Figure 6 by the ratio of time elapsed from the loading of chambers $\tau$ to the total time of coking $\tau_{c}$, while changes in heat flux received by the wall are expressed by the ratio of these changes in a given time $\Delta q_{\text {out }}$ to their average value $\Delta q^{a}$ out.

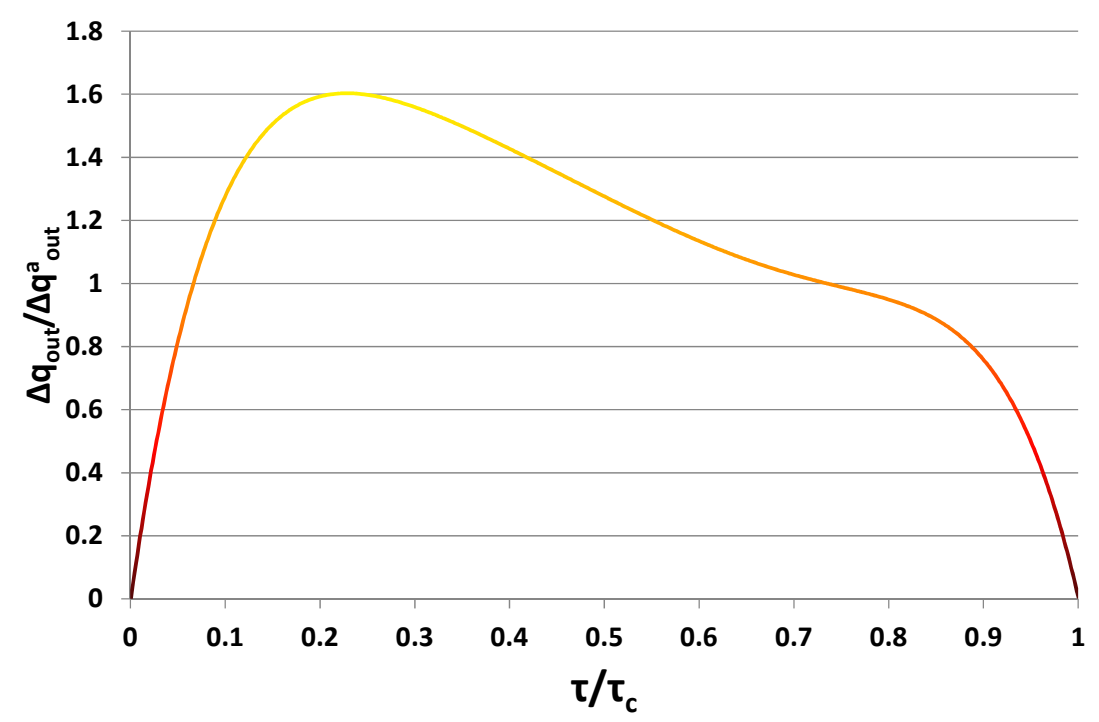

Figure 6. The average theoretical characteristics of changes in heat flux transmitted to the coking chamber wall.

Based on these data, for practical purposes it was decided to present these parameters in the form of a fourth degree polynomial (Equation (9)):

$$
\Delta \mathrm{q}_{\text {out }}(\tau)=\Delta \mathrm{q}_{\text {out }}^{\mathrm{a}}(\tau)\left(17.01 \frac{\tau}{\tau_{\mathrm{c}}}-59.044\left(\frac{\tau}{\tau_{\mathrm{c}}}\right)^{2}+77.453\left(\frac{\tau}{\tau_{\mathrm{c}}}\right)^{3}-35.425\left(\frac{\tau}{\tau_{\mathrm{c}}}\right)^{4}\right)
$$

Since the heat exchange in the considered heating flues occurs between two adjacent chambers (Figure 7), the total change in the temperature of its walls is the result of adding up temperature changes resulting from the passing time since the load of the left chamber $\left(\tau_{1}\right)$ and right chamber $\left(\tau_{2}\right)$ until the measurement moment: 


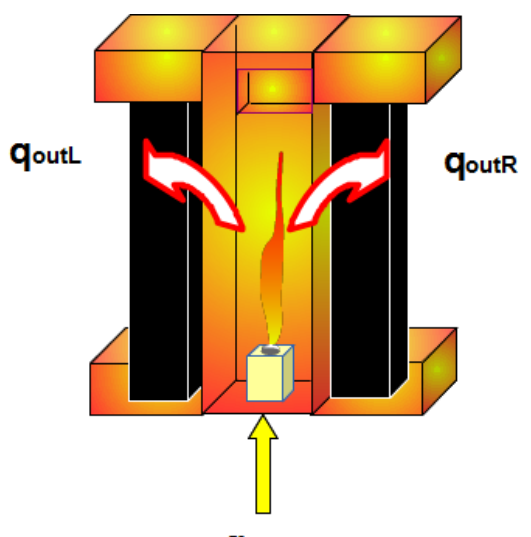

qin

Figure 7. The scheme of heat flow to the chambers on both sides of the heating flue.

Thus, taking into account the simultaneous heat exchange with the left and right walls, the polynomial presented in Equation (9) can be written in the form given in Equation (10):

$\Delta \mathrm{q}_{\text {out }}(\tau)=\Delta \mathrm{q}_{\text {out }}^{\mathrm{a}}(\tau)\left[17.01\left(\frac{\tau_{1}}{\tau_{\mathrm{c}}}+\frac{\tau_{2}}{\tau_{\mathrm{c}}}\right)-59.044\left(\left(\frac{\tau_{1}}{\tau_{\mathrm{c}}}\right)^{2}+\left(\frac{\tau_{2}}{\tau_{\mathrm{c}}}\right)^{2}\right)+77.453\left(\left(\frac{\tau_{1}}{\tau_{\mathrm{c}}}\right)^{3}+\left(\frac{\tau_{2}}{\tau_{\mathrm{c}}}\right)^{3}\right)-35.425\left(\left(\frac{\tau_{1}}{\tau_{\mathrm{c}}}\right)^{4}+\left(\frac{\tau_{2}}{\tau_{\mathrm{c}}}\right)^{4}\right)\right]$

Finally, the determination of the temperature variability in the heating flues during the coking process for a specific coke oven battery and at given operating conditions converge to the determination of the value of the proportionality factor $B=A \times \Delta q^{a}$ out $(\tau)$ for the proposed polynomial. Having a series of (n) temperature measurement results performed in heating flues $\left(T_{i}\right)$ in a specified time $\tau$ and $\tau+\Delta \tau$, and the ratios of time from the load of the chamber on the left and right side of the wall to the coking time adopted on the battery $\left(\tau_{1} / \tau_{\mathrm{c}}+\tau_{2} / \tau_{\mathrm{c}}\right)_{\mathrm{i}}$ and $\left(\left(\tau_{1}+\Delta \tau\right) / \tau_{\mathrm{c}}+\left(\tau_{2}+\Delta \tau\right) / \tau_{\mathrm{c}}\right)_{\mathrm{i}}$, the actual parameter $\mathrm{B}$ can be determined by averaging the results of comparisons of the measured temperature changes on each of the representative walls (operating in comparable conditions) during period $\Delta \tau$ with the results of their theoretical changes $\left(\Delta \mathrm{T}_{\mathrm{f}}(\tau)\right)$, what is presented in Equations (11) and (12):

$$
\mathrm{B}=\frac{\sum_{\mathrm{i}=1}^{\mathrm{n}} \frac{\mathrm{T}_{\mathrm{i}}(\tau+\Delta \tau)-\mathrm{T}_{\mathrm{i}}(\tau)}{\mathrm{T}_{\mathrm{f}}(\tau+\Delta \tau)-\mathrm{T}_{\mathrm{f}}(\tau)}}{\mathrm{n}}
$$

and:

$$
\Delta \mathrm{T}_{\mathrm{f}}(\tau)=\frac{\sum_{\mathrm{i}=1}^{\mathrm{n}} \frac{\mathrm{T}_{\mathrm{i}}(\tau+\Delta \tau)-\mathrm{T}_{\mathrm{i}}(\tau)}{\mathrm{T}_{\mathrm{f}}(\tau+\Delta \tau)-\mathrm{T}_{\mathrm{f}}(\tau)}}{\mathrm{n}}\left[17.01\left(\frac{\tau_{1}}{\tau_{\mathrm{c}}}+\frac{\tau_{2}}{\tau_{\mathrm{c}}}\right)-59.044\left(\left(\frac{\tau_{1}}{\tau_{\mathrm{c}}}\right)^{2}+\left(\frac{\tau_{2}}{\tau_{\mathrm{c}}}\right)^{2}\right)+77.453\left(\left(\frac{\tau_{1}}{\tau_{\mathrm{c}}}\right)^{3}+\left(\frac{\tau_{2}}{\tau_{\mathrm{c}}}\right)^{3}\right)-35.425\left(\left(\frac{\tau_{1}}{\tau_{\mathrm{c}}}\right)^{4}+\left(\frac{\tau_{2}}{\tau_{\mathrm{c}}}\right)^{4}\right)\right]
$$

To establish the temperature correction for individual heating flues $\mathrm{T}_{\mathrm{KS}}(\tau)_{\mathrm{i}}$, it is enough to subtract the value of its changes determined for a particular flue $\Delta \mathrm{T}_{\mathrm{f}}(\tau)_{\mathrm{i}}$ from the average temperature change value determined for all walls $\left(\Delta \mathrm{T}_{\mathrm{f}}^{\mathrm{a}}(\tau)\right)$ :

$$
\mathrm{T}_{\mathrm{KS}}(\tau)_{\mathrm{i}}=\Delta \mathrm{T}_{\mathrm{f}}^{\mathrm{a}}(\tau)-\Delta \mathrm{T}_{\mathrm{f}}(\tau)_{\mathrm{i}}
$$

\section{The Methodology of Temperature Measurements}

Taking into account the technical possibilities of assessing the temperature variability in the heating flues of individual heating walls of the coke oven battery, in the first stage it was decided to measure the temperature every $8 \mathrm{~h}$ in each seventh heating flues of all heating walls on two different batteries. These were the PWR-63 battery operating in the gravity charging system, consisting of 78 heating walls, and the PTU-57 battery operating in the stamp charging system, consisting of 58 heating walls. These batteries had correctly adjusted heating systems and worked stably. Measurements were made using a portable digital Cyclops 160L pyrometer equipped with an internal memory, from which of all 
measurement results were sent to a computer via a Universal Serial Bus (USB) interface. The time from charging of individual chambers adjacent to each of the heating walls to the moment of taking a given measurement was entered into the computer manually. Using the proposed method of temperature correction the corrected temperature of the heating flues was then calculated, separately for each of the heating walls of these batteries.

In the second stage, in order to confirm the forecasted temperature variability of the heating flues depending on the elapsed time from charging of adjacent chambers, its temperature was measured every hour in one selected heating flue with the same pyrometer as before, for the period covering the entire coking cycle. Similarly, the time from charging of individual chambers adjacent to each of the heating walls to the moment of taking a given measurement was entered into the computer manually. Then, according to the described theoretical concept, the correction of the temperature variability of the heating flues during the entire coking cycle was added to the calculated average values. Thus, while in the first stage the introduction of the described correction was aimed at eliminating the influence of the time from charging of individual chambers adjacent to each of the heating walls to the moment of making a given temperature measurement, then in the second stage it is to forecast its height for each measurement moment, regardless of when it will take place.

\section{Results}

The results of the performed temperature measurements were compared with and without the application of the procedure described in paragraph 2 . These comparisons showed that without a new correction for the variability of the recorded temperature in heating flues during coking, the deviation of results on individual walls from the average value for the whole battery reached $\pm 30 \mathrm{~K}$, while with the correction the maximum deviation did not exceed $\pm 10 \mathrm{~K}$ (Figure 8 ). Standard deviations for no corrected results were $18 \mathrm{~K}$, and $6 \mathrm{~K}$ for corrected results.

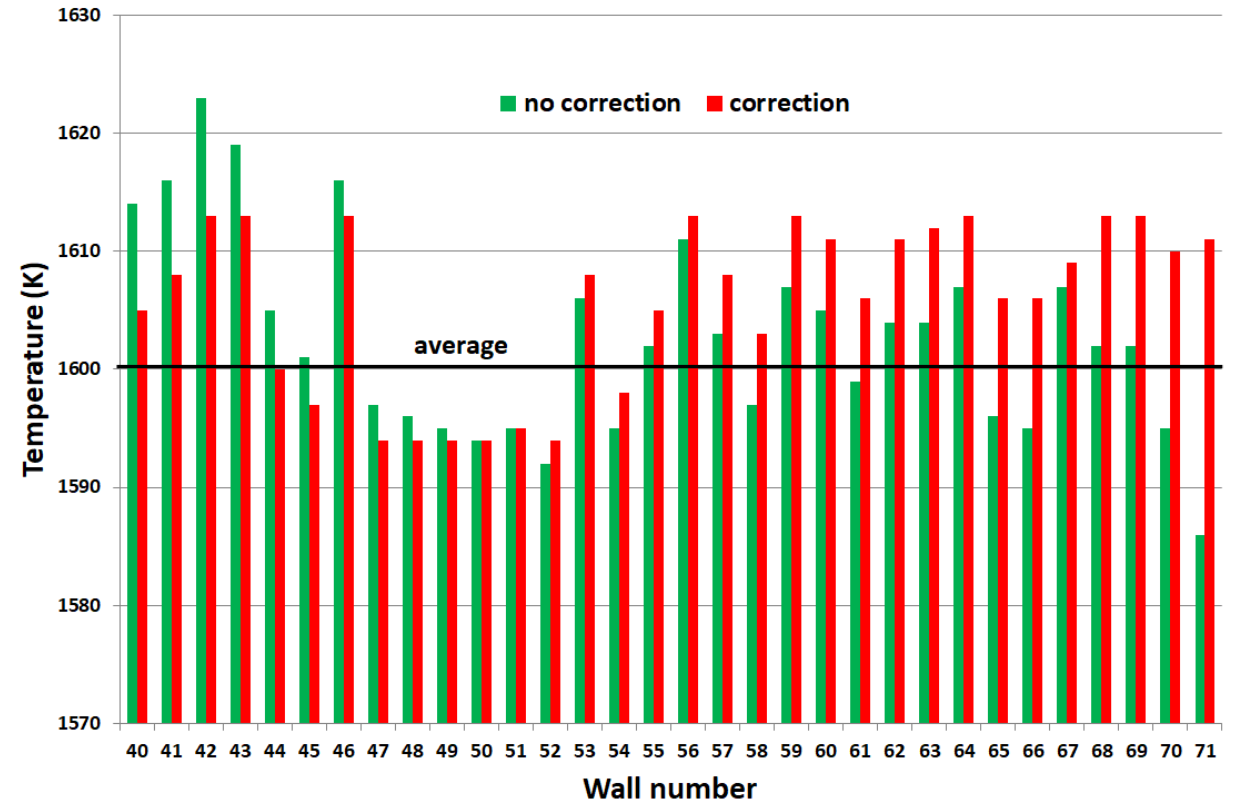

Figure 8. The results of temperature measurements in selected heating flues at one of the Polish coke oven batteries (PWR-63), without and with the use of correction coefficient.

Taking into account the obtained results, in each case the deviation of the corrected temperature measurement result from the average value is more than $10 \mathrm{~K}$ it can be regarded as a signal on the occurrence of irregularities in the place of measurement and, as 
a result, quick regulatory actions targeted on the obtaining the desired temperature level can be done by changing the stream of coke oven gas.

At the same time, to confirm the correctness of the developed procedure, temperature control was carried out in selected heating flues at one of the coke batteries in hourly intervals and the results was compared with the results of simulations carried out using the new method. The simulation consisted of adding a fixed correction to the average temperature determined on the basis of actual measurement results at a given time. The obtained results confirmed the correctness of the proposed new method. Simulation curves had the same character as the real curves, and the temperature differences at individual measuring points did not exceed $5 \mathrm{~K}$. Hence, it can be concluded that, despite possible measurement errors and simplifications adopted, the results obtained should be considered as highly satisfactory and reliable. Figure 9 shows an exemplary comparison of actual and simulated result obtained for a selected heating wall.

Cycle time of the right chamber adjacent to the wall being measured (hh:mm])

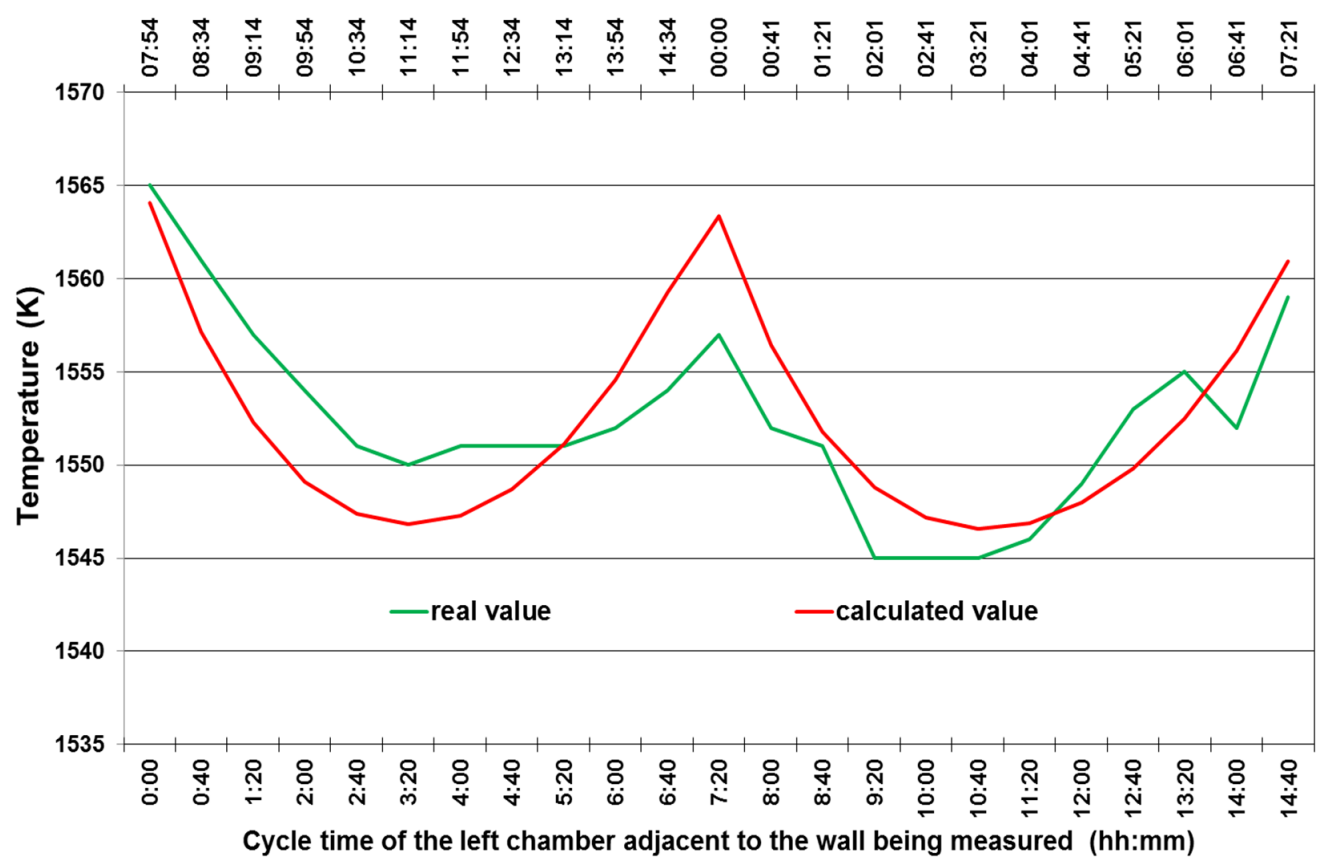

Figure 9. The comparison of the results of the actual temperature measurements in the heating flues of a selected battery (PTU-57) wall with the simulation results obtained with the use of the developed method.

The implementation of the new method of assessing the current temperature in the coke oven battery heating flues presented in the article to industrial practice will allow for more efficient performance of the coking process. It is estimated that thanks to its application, the consumption of coke oven gas used to heat the coke oven battery will be reduced by approx. 2-3\%. Although this reduction seems insignificant, given the scale of coke production in Poland, the environmental benefits obtained will be beneficial. In 2019, about 8.6 million $\mathrm{Mg}$ of coke was produced in Poland and about 2 billion $\mathrm{m}^{3}$ of coke oven gas was burned to heat all coke oven batteries. A reduction of the gas consumption by approx. $2-3 \%$ with a similar level of production would allow to reduce emissions to air associated with coke oven batteries firing. The minimal expected level of emission reduction of selected pollutants is presented in Table 1. The implementation of the developed method described in all coke oven plants in Poland will allow for achieving a real reduction in the emission levels of individual pollutants within the ranges presented below (Table 1). 
Table 1. Minimal expected emission reduction from coke oven battery heating in Poland resulting from the implementation of a new temperature assessment method in heating flues.

\begin{tabular}{cc}
\hline Substance & Expected Minimal Reduction (Mg/Year) \\
\hline carbon monoxide $(\mathrm{CO})$ & 77.4 \\
\hline carbon dioxide $\left(\mathrm{CO}_{2}\right)$ & 20,640 \\
\hline nitrogen oxides $\left(\mathrm{NO}_{\mathrm{x}}\right)$ & 25.8 \\
\hline sulphur oxides $\left(\mathrm{SO}_{\mathrm{x}}\right)$ & 19.4 \\
\hline polyaromatic hydrocarbons $(\mathrm{PAH})$ & 0.003 \\
\hline hydrogen cyanide $(\mathrm{HCN})$ & 0.03 \\
\hline $\mathrm{PM}_{10}$ & 1.3 \\
\hline
\end{tabular}

\section{Summary}

A detailed analysis of heat transfer through the coking chamber wall (from the heating flues side towards the coked coal charge side) shows its variability during the entire coking cycle. As shown in the article, this variation can be described for practical purposes by a fourth-degree polynomial.

Constant heat supply to heating flues with its variable reception causes that the temperature measured in the heating flues depends on the time of measurement. For practical purposes, it can be assumed that the change in temperature over time correlates with the changes in heat reception by the coking chamber wall. Knowing the time of the load of chambers adjacent to each of the measured heating flues and using the determined variability of heat reception through the chamber wall, it is possible to determine the expected temperature variation in the heating flues at the time of measurement.

In order to determine the range of this variability, which may be different for each coke oven battery and at given operating condition, it is enough to compare temperature measurement results with the simulation results for the pre-adopted proportionality factor (B) after each temperature measurement. On this basis, a table of corrections for the variability of the measured temperature at the time of the measurement can be developed for all heating flues of the coke oven battery (as proved by the tests and calculations).

After introducing the determined corrections, the differences in the temperature recorded in individual heating flues in relation to its average value do not exceed $\pm 10 \mathrm{~K}$, for a stable coke oven battery operation with a properly adjusted heating system, against previously noted deviations of up to $\pm 30 \mathrm{~K}$.

A significant reduction of temperature deviations noted so far allows for faster response to emerging irregularities in the heating system of individual walls of the coke oven battery, which is especially important when its regulation is to be carried out. It allows to reduce the consumption of fuel gas and to limit the emission of inherent pollutants into the atmosphere, while maintaining the required quality of coke produced. The use of the new temperature assessment method in heating flues will significantly improve the operating conditions and reliability of coke oven batteries, primarily by improving the stabilization of thermal parameters of the ceramic massif, which will minimize its damage associated with temperature fluctuations. The new correction for the variability of the recorded temperature in heating flues also allows to predict the effects of changing the order of loading of coking chambers and the duration of the adopted coking time. Such solution can be in line with circular economy idea and allow more stringent standards under the Industrial Emissions Directive (IED) and the best available techniques (BAT) for the reduction of GHG and $\mathrm{SO}_{2}, \mathrm{NO}_{\mathrm{x}}$ introduced in the European Union. 
Author Contributions: Conceptualization, L.K. and S.S. and K.G. and A.G.; methodology, L.K. and S.S. and K.G.; validation, L.K. and S.S. and K.G. and A.G. and N.I. and D.K.; formal analysis, L.K. and S.S. and K.G. and A.G. and N.I. and D.K.; investigation, L.K. and S.S. and K.G. and A.G. and N.I. and D.K.; writing-original draft preparation, L.K. and S.S. and K.G. and A.G. and N.I. and D.K.; writing-review and editing, L.K. and S.S. and K.G. and A.G. and N.I. and D.K.; visualization, L.K. and S.S. and K.G. and A.G. and N.I. and D.K. All authors have read and agreed to the published version of the manuscript.

Funding: Institute for Chemical Processing of Coal, Zamkowa 1 St, 41-803 Zabrze, Poland; Silesian University of Technology, Konarskiego 18 St, 44-100 Gliwice, Poland; Cracow University of Technology, Warszawska 24 St, 31-155 Cracow, Poland; AGH University of Science and Technology, Gramatyka 10 St, 30-076 Cracow, Poland.

Informed Consent Statement: This study did not require ethical approval.

Conflicts of Interest: The authors declare no conflict of interest.

\section{References}

1. Remus, R.; Aguado-Monsonet, M.A.; Roudier, S.; Sancho, L.D. Best Available Techniques (BAT) Reference Document for Iron and Steel Production: Industrial Emissions Directive 2010/75/EU (Integrated Pollution Prevention and Control); JRC Working Papers JRC69967; Joint Research Centre: Luxenbourg, 2013; (Seville site).

2. Kosyrczyk, L. Modelowanie pracy baterii koksowniczej i sterowanie jej eksploatacja; Wydawnictwo Instytutu Chemicznej Przeróbki Węgla: Zabrze, Poland, 2013.

3. Rejdak, M.; Bigda, R.; Wojtaszek, M. Use of alternative raw materials in coke-making: New insights in the use of lignites for blast furnace coke production. Energies 2020, 13, 2832. [CrossRef]

4. Chen, C.W.; Shen, J.F.; Hong, M.T.; Chung, K.A.; Yen, H.J. Application of the thermal state diagnosis system for coke oven battery. In Proceedings of the 3rd International Cokemaking Congress, Gent, Belgium, 16-18 September 1996; pp. 69-76.

5. Sultanguzin, I.A. Analiz processow gorenia otopitelnych gazow w koksowoj bataree. Koks I Chimia 2007, 3, 11-20. (In Russian)

6. Sultanguzin, I.A. Razrabotka edinoj kineticeskoj i diffuzionnoj modeli gorenia gazow w koksowoj bataree. Koks I Chimia 2007, 4 , 12-16. (In Russian)

7. Sultanguzin, I.A. Analiz wliania geometriceskich razmerow otopitelnogo kanala koksowoj peci na dlinu plamieni. Koks I Chimia 2007, 9, 19-22. (In Russian)

8. Smołka, J.; Słupik, Ł.; Fic, A.; Nowak, A.J.; Kosyrczyk, L. 3-D coupled CFD model of a periodic operation of a heating flue and coke ovens in a coke oven battery. Fuel 2016, 165, 94-104. [CrossRef]

9. Huhn, F.; Strelow, F.; Eisenhut, W. The influence of particular raw material and operating parameters on the coking mechanism. Rev. Met. Paris 1992, 89, 635-644. [CrossRef]

10. He-Ming, D.; Qian, D.; Dun, L.; Zhao-Yang, C.; Jian-Min, G.; Shao-Hua, W. Impacts of organic structures and inherent minerals of coal on soot formation during pyrolysis. Energies 2019, 12, 4410. [CrossRef]

11. Zhang, A.Q.; Feng, Y.H.; Zhang, X.X.; Wang, M.D.; Yang, J.F.; Xu, Y. Decoupling simulation of thermal processes in coupled combustion and coking chambers of a coke oven. ISIJ International 2013, 53, 995-1001. [CrossRef]

12. Ściążko, M.; Sobolewski, A. Prognozowanie jakości koksu; Wydawnictwo Instytutu Chemicznej Przeróbki Węgla: Zabrze, Poland, 2015.

13. Ściążko, M.; Mertas, B.; Kosyrczyk, L.; Sobolewski, A. A predictive model for coal coking based on product yield and energy balance. Energies 2020, 13, 4953. [CrossRef] 